\title{
Try Before You Buy: How to Design Information Systems to Enhance Consumer Willingness to Test Sustainable Innovations
}

\author{
Carola Stryja ${ }^{1 *}$ and Gerhard Satzger ${ }^{1}$
}

\begin{abstract}
More and more business organizations recognize the relevance of sustainable innovations as driving factor for their corporate strategies, products and processes. But while the concept of sustainability is generally ratified by employees and consumers, their willingness to actually use or buy such innovations can be low. One of the most important facilitators for the adoption of innovations is self-experience generated by testing the innovation. This paper provides insight on how sustainable innovation testing affects consumer mindsets and which barriers consumers face when considering testing a sustainable innovation. The study draws on the data from an in-depth interview study with seven providers and consumers of electric cars (as sustainable innovation) in business and private environments. Insights about the nature of consumer's willingness to test are extracted and recommendations for the design and use of information systems as facilitators for testing sustainable innovations are derived.
\end{abstract}

Keywords: sustainable innovation; e-car, interview study; barriers; trial; decision design

Submitted: July 26 ${ }^{\text {th }}, 2017$ / Approved: April 16 ${ }^{\text {th }}, 2018$

\section{Introduction}

In today's corporate business strategies sustainability plays a central role as consumers are becoming increasingly aware of the environmental consequences of their purchases (Fraj \& Martinez, 2007). Corporations respond to this development by increasing the share of sustainable products and services in their portfolios, by adjusting internal processes to sustainability guidelines or by enhancing the sustainability of the whole supply chain (Melville, 2010). In general, the concept of sustainability is widely accepted and supported by providers and consumers. However, in contrast to this acceptance it can be observed that consumers or employees resist to purchase or use sustainable innovations (Pichert \& Katsikopolous, 2008). Such a resistance, however, is only partially related to the innovation itself. Even if consumers are open to environmental topics, it is not ensured that they also will adopt sustainable innovations (Ozaki, 2011). Whether a consumer behave in a sustainable way is strongly determined by their value system and personality (Kollmuss \& Agyeman, 2002). Living sustainable almost always means a change from longestablished habits towards new behavioral patterns (Kollmuss \& Agyeman, 2002). Since consumers tend to stick to their established behaviors they are less open to new alternatives even if they have the option on superior choices (Heidenreich \& Handrich, 2014; Laumer, Maier, Eckhardt, \& Weitzel, 2016; Samuelson \& Zeckhauser, 1988). To enhance the adoption of sustainable innovations, one has to motivate consumers to open up to behavioral change and test them. Trial strongly affects the perception of the innovation because it provides a direct sensory experience which is perceived as more trustworthy as indirect advertisements (Kempf \& Smith, 1998). Furthermore, there is evidence that product trial causes feelings of attachment and partial adaptation of ownership caused by the endowment effect (Wolf, Arkes, \& Muhanna, 2008). To induce behavioral change and get more consumers engaging in testing sustainable innovations, predictors and antecedents of consumer's willingness to test must be adequately addressed in information systems. Interfaces like apps, web pages or online platforms are commonly used facilitators of behavioral change (Weinmann, Schneider, \& von Brocke, 2015). Thus, to enhance sustainable behavior in industry and society it is crucial to better understand how to design such information systems to promote sustainable decision-making (Melville, 2010). There is still lack of knowledge on how to design information systems to enhance consumer openness towards innovation testing and induce behavioral change (Benartzi \& Lehrer, 2015).

In this study, electric cars (e-cars) are chosen as example for a sustainable innovation. Establishing e-cars in society is of governmental interest to reduce environmental pollution and ensure the fulfillment of the climate goals of the European Union (Jochem, Babrowski, \& Fichtner, 2015). Until 2050, industry and society have to have reduced greenhouse gas emissions of transport by up to $60 \%$ - a reduction which is only feasible with alternative and more sustainable propulsion technologies (Abdelkafi, Makhotin, \& Posselt, 2013; Stryja, Satzger, \& Dorner, 2017). The problem of e-cars is their missing market acceptance, i.e. despite their environmental benefits, they are still perceived as inferior choice compared to diesel or gasoline cars (Dudenhöffer, 2013). However, research shows that once consumers have tested them, their perceptions of e-cars are favorably affected (Bühler, Cocron, Neumann, Franke, \& Krems, 2014). This study addresses the lack of knowledge on how information system design may influence decision-making in terms of sustainability. It aims to answer the questions of (1) how innovation (e-car) testing affects consumer mindset, (2) what hinders consumers from testing e-cars and (3) which information system design options may enhance consumer motivation to test them.

(1) Karlsruhe Service Research Institute, Karlsruhe Institute of Technology, Kaiserstr. 89, 76131 Karlsruhe, Germany ${ }^{*}$ Corresponding author: carola.stryja@kit.edu 


\section{Methodology}

The data reported in this paper has been collected within seven indepth interviews conducted with providers and consumers of e-cars to consider the perspectives of both interest groups. For the provider side four representatives from business organizations that sell e-cars as part of their sustainable product portfolio or use them in their corporate car fleet as contribution to the organizational sustainability strategy were asked. As for the consumer side three private users were interviewed to gain insight about topics relevant in the private context of e-car testing. Participants were sampled by following two criteria: role and experience.
As providers, they must be in a position where they have a promoter role for e-cars in their organization, i.e. trying to enhance their usage or sales numbers. As consumers, they must be in a position where purchase or usage of e-cars are a realistic scenario for them, i.e. being capable to afford a car and being in a situation where the use of a car makes sense in case of work and private life. Participants of both groups should have experience with e-cars to ensure a certain depth of content in their responses. For providers, a minimum experience in their position of 2 years were determined while consumers should have experienced at least one detailed test drive (more than $30 \mathrm{~min}$.) to be able to speak about the topic. Participant's profiles are provided in Table 1.

Table 1. Participant's profiles

\begin{tabular}{|c|c|c|c|c|}
\hline 1 & $\mathrm{n} / \mathrm{a}$ & Provider & Marketing and Sales Representative & 5 years \\
\hline 2 & $\mathrm{n} / \mathrm{a}$ & Provider & Sales Manager & 3 years \\
\hline 3 & $\mathrm{n} / \mathrm{a}$ & Provider & Consultant & 7 years \\
\hline 5 & 28 & Consumer & Researcher & Test of e-cars $(3 \mathrm{x})$ \\
\hline 6 & 28 & Consumer & Software Engineer & $\begin{array}{c}\text { Regular use of e-cars in carsharing } \\
(8-10 \mathrm{x} / \text { month })\end{array}$ \\
\hline 7 & 35 & Consumer & Consultant & Test of e-car (1x) \\
\hline
\end{tabular}

All interviews followed a semi-structured guideline with several question blocks. Open questions were used to give the interview partner the possibility to share as much expertise as possible. As provider and consumer have different views on the same topic questions in the interview guideline were adapted to both groups with the result of having two similar but slightly different question sets. Providers were asked about the e-car test process in their organization, the willingness to test among their employees and customers and their barriers. The current use of information systems and potential ideas for a more effective use regarding testing motivation were discussed resulting in a set of 22 questions. Consumers were asked about their test experience, the willingness to test among their private environment and testing barriers. In addition, recommendations for the design of test drives and the use of information systems to facilitate them were discussed resulting in a set of 19 questions. Each interview lasted between $30 \mathrm{~min}$ (shortest duration) and $90 \mathrm{~min}$ (longest duration) and was conducted in a face-to-face conversation held by one interviewer. Six interviews were recorded and transcribed afterwards. One participant disagreed to the interview recording. For this interview notes were taken during the conversation.

The analysis of the interviews followed the qualitative content analysis of Mayring (1991) in which essential statements in the material are extracted subsequently. The extraction process is based on an iterative process of paraphrasing, reducing and aggregating statements relevant to the research question. In doing so statements are generalized repeatedly to achieve a higher level of abstraction necessary for subsequent analyses (Mayring, 1991). In this study, full transcripts were available for six interviews, three relating to electric car providers and three relating to electric car consumers. For one interview with a provider conversation notes were used for the analysis. Participant statements were first grouped according to the question they belong to before then being paraphrased resulting in a set of 227 statements from providers and 136 statements from consumers. In a second step the statements were coded according to the two-cycle recommendations of Saldana (2009). Data was first descriptive-coded by summarizing the basic topic of a statement in a word or short phrase (Miles \& Huberman, 1994; Saldaña, 2009). Common statements were selected and used as first set of coding categories which were then patterncoded in the second cycle to identify major themes in the data (Miles \& Huberman, 1994; Saldaña, 2009). Both groups, providers and consumers, were analyzed separately due to the different set of questions. Results on the same topic (e.g. willingness to test or barriers) were extracted separately and merged for the presentation in the paper. To clarify the resilience of the data, three levels of evidence were used to classify the quality of each major topic. The level of evidence of a major topic calculates as mean value of the cumulative share of the topic's appearance in all provider and consumer statements. Depending on the mean value, the level of evidence is "strong" (mean value $>25 \%$ ), "moderate" (mean value $>=12.5 \%$ ) and "low" (mean value $<12.5 \%$ ). 


\section{Results}

In this section key results of the data analysis are presented and discussed. Results will not be distinguished into provider and consumer statement if the statement has a general nature. A summary of key topics, whether they appeared in provider and/or consumer statements and their strength of evidence are provided in Table 2. In the following sections the findings and the evidence for them are discussed in more detail. Direct quotes in the text are verbatim.

\section{Current consumer willingness to test e-cars}

The interview participants were asked about the willingness of their customers, employees or private environment (family, friends and colleagues). In general, all three groups are generally open towards the technology but have a low willingness to test. Employees and custo- mers from the e-car providers seem to be more willing to test than the private environment of the consumers. Interest and curiosity to drive an innovative car play an important role for the willingness to test. Also important is whether the e-car will be usable for the employees later. Almost all providers emphasize that most of their employees and customers would test if they would have the opportunity. Those who show a strong resistance towards testing only form a small group. However, test convenience is important as especially consumers who already own a car do not come in touch with e-cars in everyday life. Test drives would only be used if they would be "handed to them on a silver platter" (consumer statement). Incentives like test voucher or increasing the presence in media might also help to enhance visibility. Especially in the context of car sharing the willingness to test is surprisingly low.

Table 2. Summary of key findings and supporting evidence

\begin{tabular}{|c|c|c|c|c|c|}
\hline \multicolumn{2}{|r|}{ Theme } & Major Topic & $\begin{array}{l}\text { Provider } \\
\text { statement }\end{array}$ & $\begin{array}{l}\text { Consumer } \\
\text { statement }\end{array}$ & $\begin{array}{l}\text { Strength of } \\
\text { evidence }\end{array}$ \\
\hline \multirow{8}{*}{1} & \multirow{8}{*}{$\begin{array}{l}\text { Consumer willingness } \\
\text { to test } \\
\text { e-cars }\end{array}$} & Openness towards technology but low willingness to test & $\mathrm{x}$ & $\mathrm{x}$ & Strong \\
\hline & & Willing to test because of future relevance & $\mathrm{x}$ & $\mathrm{x}$ & Moderate \\
\hline & & Willing to test if convenient & $\mathrm{x}$ & $\mathrm{x}$ & Moderate \\
\hline & & Willing to test if incentives are provided & $\mathrm{x}$ & $\mathrm{x}$ & Moderate \\
\hline & & Willing to test if e-cars are on the spot in media & & $\mathrm{x}$ & Low \\
\hline & & Willingness depends on age bands & $\mathrm{x}$ & $\mathrm{x}$ & Low \\
\hline & & Low willingness due to missing touching points with e-cars in daily life & & $\mathrm{x}$ & Low \\
\hline & & High willingness due to technological affinity & & $\mathrm{x}$ & Low \\
\hline \multirow{7}{*}{2} & \multirow{7}{*}{$\begin{array}{l}\text { Effect of testing on } \\
\text { changing consumer } \\
\text { mindsets }\end{array}$} & Removal of doubts about technological functionalities & $\mathrm{x}$ & $\mathrm{x}$ & Strong \\
\hline & & Illustration of technological benefits arouses enthusiasm & $\mathrm{x}$ & $\mathrm{x}$ & Strong \\
\hline & & Raise of general consumer awareness for e-cars & & $\mathrm{x}$ & Low \\
\hline & & Realization of e-cars as forward-looking mobility technology & & $\mathrm{x}$ & Low \\
\hline & & Comparison with features of own car & & $\mathrm{x}$ & Low \\
\hline & & Creation of trust in technology & & $\mathrm{x}$ & Low \\
\hline & & Encouragement of reflection about own driving behavior & $\mathrm{x}$ & & Low \\
\hline \multirow{5}{*}{3} & \multirow{5}{*}{$\begin{array}{l}\text { Barriers that prevent } \\
\text { e-car testing }\end{array}$} & $\begin{array}{l}\text { Maturity level of battery and infrastructure too low to match consumer } \\
\text { requirements }\end{array}$ & $\mathrm{x}$ & $\mathrm{x}$ & Strong \\
\hline & & Operation of e-cars not economically manageable & $\mathrm{x}$ & $\mathrm{x}$ & Moderate \\
\hline & & General refusal of e-car technology & $\mathrm{x}$ & $\mathrm{x}$ & Moderate \\
\hline & & Features of e-car are perceived as minor than those of car currently owned & $\mathrm{x}$ & $\mathrm{x}$ & Low \\
\hline & & Fear of not being able to handle challenges of e-car driving & $\mathrm{x}$ & $\mathrm{x}$ & Low \\
\hline \multirow{7}{*}{4} & \multirow{7}{*}{$\begin{array}{l}\text { Recommendations for } \\
\text { the design and use of IS } \\
\text { to motivate e-car testing }\end{array}$} & Make booking process and test event as convenient as possible & $\mathrm{x}$ & $\mathrm{x}$ & Strong \\
\hline & & Place e-cars at prominent positions (e.g. landing page) & $\mathrm{x}$ & $\mathrm{x}$ & Strong \\
\hline & & Highlight e-cars with symbols or slogans (e.g. green leaf) & & $\mathrm{x}$ & Moderate \\
\hline & & Incentivize with vouchers or discounts & $\mathrm{x}$ & $\mathrm{x}$ & Low \\
\hline & & Call on good conscience (e.g. slogans) & & $\mathrm{x}$ & Low \\
\hline & & Use of testimonials who already tested e-cars or reports from friends on social media & & $\mathrm{x}$ & Low \\
\hline & & $\begin{array}{l}\text { Proposal of e-car if application case is predestined for e-cars (e.g. rental e-car for } \\
\text { one-way trip) }\end{array}$ & & $\mathrm{x}$ & Low \\
\hline
\end{tabular}


Here, younger customers are the group which book such cars more often while older members tend to be more hesitant. Technology affinity also plays a role for openness. Consumer participants reported that friends with a higher interest in technology are more open to try out e-cars. In total, there is evidence that consumers are in general open towards the technology but with a low willingness to take the effort to test it. Testing should therefore be made as convenient as possible and to be integrated in every day life such that consumers with no awareness can get in touch with e-cars easily.

\section{The effect of e-car testing on changing consumer mindsets}

Self-experience is one of the key elements for the formation of an individual's opinion. Only by making the experience of touching and using the innovation one is able to comprehensively evaluate its individual usefulness. General effects of testing and effect causes have already been discussed in section 2 . This section elaborates how specifically testing of e-cars changes consumer mindsets and usage behavior. All interview partners explicitly mentioned that their e-car test drives (or those of their customers) had removed doubts about the technological functionality. Concerns regarding complexity and effort of charging were identified as being less powerful than imagined. In most cases the perception of the technology was very positive. Driving the e-car was perceived as being much easier and more convenient than driving conventional cars (e.g. 17-inch touch display in the dashboard, no gearbox). Consumers state the problem of teething troubles which prevents them from e-car purchase. As long as the problems of low battery range and weak charging infrastructure are not solved and no standards exist investing in e-cars is perceived as too risky. To remove functionality doubts it is important that consumers can test the e-car for enough time and in application cases similar to their daily use behavior. The approach of Tesla to provide a consultant during the test drive has been experienced as very useful as questions could have been answered instantly. Also, additional information on potential costs and benefits was provided to the consumer which the person did not consider beforehand (e.g. maintenance costs, battery warranty). The issue of heavy batteries and related acceleration problems could also be disproved. In total, simplicity of concepts - be it in the car or in the organization of the test drive - convinces consumers. The easier it is to test the more positive the opinion of the technology. Besides removing doubts about the functionality testing has the powerful effect of visualizing and illustrating the benefits of an innovation. In case of e-cars consumers were fascinated from the quietness in the car (especially useful for business calls) and the instant acceleration when pushing the gas pedal. The car was so silent that some consumers did not even noticed it has started when pushing the ignition button or using the ignition key. Emotions before the test drive are described by the consumer participants as "looking forward" and "being curious" and after the test drive as "positive" and "good". Several participants mentioned that they had the feeling of anticipating the future while driving the e-car. Testing convinced them that e-cars will be the car technology of the future. Driving comfort, innovation factor, handling simplicity, acceleration and the feeling of doing a good action to the environment are factors that cause enthusiasm. One participant explicitly states:
"Without testing the e-car I would still be interested but I would not be that fascinated I am now." Both effects, removing doubts and creating enthusiasm by illustrating the benefits, have been stated repeatedly in both participant groups while other effects appeared less in the data. Nevertheless, they offer interesting perspectives on the topic and have thus been included in the paper. As mentioned in an earlier section raising consumer's awareness for the innovation and overcoming the "convenience barrier" is the critical point for providers. Presenting e-cars at mass events or as rewards for loyal customers are some of the activities which may help. The consumer with one test experience explicitly states that testing the e-car has raised general awareness of the topic in media and daily life significantly. Because the display of the driving range gives instant feedback on driving behavior (e.g. a strong decrease in range when pushing the gas pedal too powerful) drivers are encouraged to critically reflect their driving behavior. The realization that e-cars have the capability to be the leading mobility technology of the future is another observed effect. It can be said that testing creates trust in the technology where there has been doubt beforehand.

\section{Barriers that prevent consumers from e-car testing}

During the analysis of the interview data it got more and more obvious that the interview participants had difficulties to name barriers which prevents consumers actually from testing and not from the technology itself. Barriers stated in the direct responses of the interview partners to the question mainly comprise barriers towards the technology itself. However, it is important to emphasize that practical barriers like missing convenience, missing awareness of the technology etc. can be barriers to testing, too. As they have only be stated indirectly in the responses to other questions, those factors are not presented in this section but are considered in the recommendations section later. The barriers explicitly stated in the interview responses are summarized in the following section. It is no surprise that most providers and consumer participants state technological immaturity as main barrier. Skepticism regarding driving range, charging times and availability of charging stations in public are factors that prevent consumers from getting in touch with e-cars. Most people are not used to the impact their driving behavior has on their driving range as it is the case with e-cars. Some consumers state this impact as limiting factor for their enthusiasm for the technology in general. Depending on the e-car model, a driving range actually can be a limiting factor. In the context of car sharing e-cars are not booked due to the fear of customers to find the battery only half loaded when they arrive at the car because the user before just returned the car. To address the fear the car sharing company offers a free change to another car if the battery is insufficiently loaded. As side effect of such concerns, operating e-cars - for providers as well as consumers - is considered as not being economically manageable. High investment costs in car and charging infrastructure deters consumers from adopting the technology. Furthermore, due to the low oil price and limited driving range, e-cars are not considered as economically reasonable alternative to conventional cars. Especially in the case of e-cars as corporate cars investment costs play an important role as they have to be paid partly by the employee through a monthly fee. As in corporate 
car contracts cover gas and maintenance costs are usually covered by the employer there is the problem that by choosing an e-car the employee anticipates higher investment costs but does not profit from lower operating costs. E-cars are perceived as inferior choices. Besides functional issues a general refusal of the technology can be observed, too. Interview participants of both groups state that there is no willingness to behavior change in case of charging or driving manner. Effort for charging is perceived as being too high and even the use of Tesla superchargers is refused due to being too complex. Observing the influence of individual driving manner on the driving range is perceived as being restrictive and a fun killer. Resistant consumers who close their mind to the technology do not appreciate the necessity of testing due to the assumption that e-cars in general will not work for them. While closed-mindedness is a barrier relatively difficult to overcome for providers, the last two barriers observed in the data offer more possibilities for interaction and conviction. Especially consumers who own a car are instantly comparing the features of the e-car with those of their car currently owned. Missing engine noise, different power levels of e-cars compared with high investment costs induce a feeling of inferiority of the e-car. It is important to encourage those testers to rethink their approach towards driving in general. An interesting barrier mentioned by both participant groups is the fear of not being capable to manage the charging and driving process. One consumer participant explicitly states that the personal environment perceives themselves as well as the technology as not being mature enough for adoption.

\section{Recommendations for the design and use of information systems to motivate e-car testing}

The factor which influences a consumer's decision to make a test drive by far the most is the perceived convenience. Especially when there is no hype on the innovation which encourages consumers automatically, convenient test drives are important means for adoption probability. E-cars itself do not motivate for more effort. Making the booking and test process as easy and convenient as possible has thus been emphasized by all participants and with strong evidence. Test opportunities should be provided at places that are easy to reach. For example, in car sharing, consumers are not willing to walk an extra mile to drive an e-car. Test drives should be for free and without obligations (e.g. not being charged for refilling the battery after driving) for the consumer. Consumers should not have the feeling of being actively persuaded to do something they are not willing to do. The booking process should be as pleasant and simple as possible (e.g. by using a large, simple booking button). The visit in the car dealership can therefor already be a barrier itself (e.g. the perception of having to adhere to a certain dress code): "This is like a wall and a completely different experience as compared to the landing page I was navigated to by a simple Google search." Placing the e-car on a prominent position on the website's landing page or in the booking system is a simple yet powerful tool to enhance consumer awareness. Just by being aware of e-cars more consumers will consider them in their decision-making process. Prominent placement has the effect that e-cars are perceived as being something special and worth to be considered as serious al- ternative to conventional cars. Provider and consumer participants repeatedly emphasized the large potential of such promotions. Placing e-cars at the top position in car sharing or rental car booking platforms will induce a higher willingness to click on those models (like the first search page or Google or the partner hotels in booking. com). As one consumer states: "I believe there is a huge potential regarding positioning and presentation of e-cars in booking scenarios." One consumer participants described how s/he made the impressive experience of a taxi drive with a Tesla and afterwards saved this taxi driver as favorite in the taxi booking app to accelerate future bookings. Especially in the business context rental cars are often booked by using a consumer hotline. Here, providers can propose e-cars. Besides convenience and prominent placing, using symbols or other visualizations enhances visibility and consumer motivation to consider e-cars. Being announced as "novelty" or marked with a symbol for ecological friendliness (e.g. tree or green leaf) is proposed as promising means by consumer participants. Using conventional marketing tools like incentives or vouchers might enhance motivation further (see also section "Test scenarios". An interesting topic which occurred in the consumer participant data was the effect of calling on the good conscience of the consumer. As example, one car sharing company is named which builds on this mechanism by providing a small leaf in the car dashboard. Depending on the driving behavior, the leaf changes from green to red. A similar mechanism could be implemented as feedback when booking a conventional car sharing or rental car with a high carbon dioxide emission. Using slogans that promote eco-friendly choice behavior in an appealing manner might be another way. Since experiences from friends and colleagues are an important motivation factor, using testimonials who actively use e-cars or at least have tested them can be useful to enhance credibility in the innovation. The psychological factor of observing the functionality of the technology is important. Using test reports on websites or integrate experiences shared in social media in booking platforms may further options to consider for providers. Especially car rental companies often face the challenge that consumers need the car only one-way. For this inquiries e-cars could be actively proposed by the booking system by selecting them as the most appropriate and eco-friendly car.

\section{Discussion}

To understand the reasons that drive consumers to (not) test a sustainable innovation like e-cars and how information systems can be used to enhance the willingness for innovation testing has been the thrust of the analysis. The study contributes by giving a comprehensive view on the question how information systems can be used to support the adoption of sustainable innovations. Although the study has been conducted in the context of e-cars its findings offer interesting insights that may also be valid for innovations with similar characteristics and problems. By conducting interviews with representatives from the provider and consumer side, a deeper understanding of both perspectives was possible. Furthermore, providers were selected according to the premise to cover all possible ways of e-car adoption: purchase (car dealer), usage in car sharing (car sharing provider), usage in business fleet (retailer) and corporate car (consultancy). 
The study contributes to previous work by elaborating barriers and effects of testing for a sustainable innovation at the case of e-cars. Since the character of the study was an exploratory one it never has been the goal to present statistically validated constructs at the end. In contrast, the thrust of the research undertaken was to illustrate the nature of the phenomenon that innovations which are accepted and approved by consumers as being forward-looking technologies face such difficulties to attract consumers to test and adopt them. This attitude-behavior gap can be observed in many cases but especially in the case of pro-environmental behavior (Kollmuss \& Agyeman, 2002). The results of the study allow a clearer understanding of the factors behind this gap in case of e-cars. It was interesting to observe the relevance of convenience for consumer willingness to test. To close this behavior-attitude gap using information systems is the premise of this work. Thus, important design elements that facilitate e-car testing (as one form of pro-environmental behavior) were collected in the conversations and elaborated in the interview analysis. The recommendations presented in this paper provide clear and simple insights which can be useful stepping stones for practitioners and scholars. Marketing managers can use them as concrete instructions for the design of their website or booking systems. By being aware of test barriers, the promotion of test offerings can be designed to by-pass those factors. Currently, the potential of information systems as means to promote e-car testing is rudimentary exploited by e-car providers. The application of the design guidelines proposed in the paper offers a high potential of attracting more consumers to testing - and potentially adopting - e-cars. Further research on the effect of their application on consumer choice behavior might generate further interesting insights on the topic.

This research has some limitations, though. First, the small sample of seven interviews is not representative and thus allows a limited generalization of the findings. While the small number of interviews allowed an in-depth analysis of the statements, it would be necessary to state the questions to a larger sample to verify the statements made. Second, participants of the consumer sample show a slightly pro-technology bias due to their age, profession and attitude. It would be necessary to include also elderly consumers in the sample to gain a more realistic view on the motives behind their choices. Third, all consumers have made test experiences with the models of Tesla which use their own well established charging infrastructure. Experiences gained in such test drives are not representative for other ecar models. However, Tesla shows how the e-car technology should (and one day will) be working and is currently maybe the only way to experience the real potential of an e-car as problems not relating to the technology itself (e.g. missing infrastructure) are already solved. But despite these limitations, insights from this study may serve as valuable starting points for further research or as inspiration for practitioners to consider the relevance of innovation presentation in information systems.

\section{Conclusion}

While sustainable innovations like e-cars are mentally accepted by consumers their adoption rate is still on a low level. Consumers who are open to environmental topics are not automatically those who also adopt such a sustainable innovation. Rational reasons like an insufficient technological maturity or the uneconomic operation of e-cars may be one explanation for such consumer behavior. The goal of this study however was to dig deeper to identify hidden factors that prevent consumers from even considering the test of e-cars while being generally open to their use. As testing a new product comes in general without any obligations there is the question why so few consumers are willing to test e-cars. Results from this study provide answers to this question. By conducting seven in-depth interviews with providers and consumers of e-cars, it was possible to gain insight from both perspectives on the problem. Results show that test events should be as convenient and playful as possible, ideally embedded in cooperations with other organizations like restaurants or provider of adventure trips. The greatest effects of testing lie in removing doubts on functionality and create an emotional bond to the e-car by arousing enthusiasm. The study also shows why so few consumers are actually testing e-cars. Missing convenience and incentives, low presence in media, missing touching points in everyday life and possible restraint because of age are factors which occurred in the data. Some of them can be addressed by designing and using information systems appropriately. Placing e-cars at prominent places on website or in the booking system may one option. Highlighting with symbols and calling on good conscience are further possibilities for the design of information systems. The study results contribute to innovation resistance theory, theory of product trial, choice architecture and research on decision support systems. To gain more knowledge about an appropriate and effective design of information systems to influence consumer testing behavior was the scope of this study. By analyzing the current use of information systems in e-car test marketing and by giving recommendations for persuasive design and use of such systems this study provides several links for further research.

\section{References}

Abdelkafi, N., Makhotin, S., \& Posselt, T. (2013). Business Model Innovations for Electric Mobility - What Can Be Learned From Existing Business Model Patterns? International Journal of Innovation Management, 17(1), 1340003-1-1340003-41. http://doi.org/10.1142/ S1363919613400033

Benartzi, S., \& Lehrer, J. (2015). The Smarter Screen: Surprising Ways to Influence and Improve Online Behavior. New York: Penguin.

Bühler, F., Cocron, P., Neumann, I., Franke, T., \& Krems, J. F. (2014). Is EV experience related to EV acceptance? Results from a German field study. Transportation Research Part F: Traffic Psychology and Behaviour, 25, 34-49. http://doi.org/10.1016/j.trf.2014.05.002

Dudenhöffer, K. (2013). Why electric vehicles failed. Journal of Management Control, 24(2), 95-124. http://doi.org/10.1007/s00187-013-0174-2

Fraj, E., \& Martinez, E. (2007). Ecological consumer behaviour: an empirical analysis. International Journal of Consumer Studies, 31, 2633. http://doi.org/10.1111/j.1470-6431.2006.00565.x 
Heidenreich, S., \& Handrich, M. (2014). What about Passive Innovation Resistance? Investigating Adoption-Related Behavior from a Resistance Perspective. Journal of Product Innovation Management, 32(6), 878-903. https://doi.org/10.1111/jpim.12161

Holzer, H. (2015). Die Spannung lässt nach. Retrieved June 14, 2016, from http://www.zeit.de/mobilitaet/2015-09/carsharing-elektroautoprobleme

Jochem, P., Babrowski, S., \& Fichtner, W. (2015). Assessing CO2 Emissions of Electric Vehicles in Germany in 2030. Transportation Research A: Policy and Practice, 78, 68-83. https://doi.org/10.1016/j. tra.2015.05.007

Kempf, D. S., \& Smith, R. E. (1998). Consumer Processing of Product Trial and the Influence of Prior Advertising: A Structural Modeling Approach. Journal of Marketing Research, 35(3), 325. http://doi. org/10.2307/3152031

Kollmuss, A., \& Agyeman, J. (2002). Mind the Gap: Why do people act environmentally and what are the barriers to pro-environmental behavior? Environmental Education Research, 8(3), 239-260. https:// doi.org/10.1080/13504620220145401

Laumer, S., Maier, C., Eckhardt, A., \& Weitzel, T. (2016). Work Routines as an Object of Resistance During Information Systems Implementations: Theoretical Foundation and Empirical Evidence. European Journal of Information Systems, 25, 317-343. https://doi. org/10.1057/ejis.2016.1

Mayring, P. (1991). Qualitative Inhaltsanalyse. In U. Flick, E. von Kardoff, H. Keupp, L. von Rosenstiel, \& S. Wolff (Eds.), Handbuch qualitative Forschung: Grundlagen, Konzepte, Methoden und Anwendungen (pp. 209-213). Psychologie Verl. Union.
Melville, N. P. (2010). Information Systems Innovation for Environmental Sustainability. MIS Quarterly, 34(1), 1-21. https://doi. org/10.2307/20721412

Miles, M. B., \& Huberman, A. M. (1994). Qualitative data analysis. Thousand Oaks, CA: Sage.

Ozaki, R. (2011). Adopting sustainable innovation: What makes consumers sign up to green electricity? Business Strategy and the Environment, 20(1), 1-17. http://doi.org/10.1002/bse.650

Pichert, D., \& Katsikopolous, K. V. (2008). Green defaults: Information presentation and pro-environmental behaviour. Journal of Environmental Psychology, 28, 63-73. http://doi. org/10.1108/07363760210420540

Saldaña, J. (2009). The Coding Manual for Qualitative Researchers. Sage Publishing.

Samuelson, W., \& Zeckhauser, R. (1988). Status quo bias in decision making. Journal of Risk and Uncertainty, 1(1), 7-59. http://doi. org/10.1007/BF00055564

Stryja, C., Satzger, G., \& Dorner, V. (2017). A Decision Support System Design to Overcome Resistance Towards Sustainable Innovations. In Proceedings of the 25th European Conference on Information Systems (ECIS) (pp. 2885-2895). Guimarães, Portugal, June 5-10, 2017.

Weinmann, M., Schneider, C., \& von Brocke, J. (2015). Digital Nudging. http://ssrn.com/abstract=2708250.

Wolf, J. R., Arkes, H. R., \& Muhanna, W. A. (2008). The power of touch: An examination of the effect of duration of physical contact on the valuation of objects. Judgment and Decision Making, 3(6), 476-482. 
